\title{
Applied Mathematical Approach for Decision-Making in Building Plan Design
}

\author{
Grit Ngowtanasuwan \\ Faculty of Architecture, Urban and Creative Art, \\ Mahasarakham University, Mahasarakham 44150, Thailand \\ grit_n@hotmail.com
}

\begin{abstract}
This article presents a method for solving decision in building plan design by using a mathematical model (nonlinear programming). First objective is to formulate mathematical models for analysis in dividing rooms and dimensions in a building plan. Secondly, to calculate the dimensions and room sizes which have minimum construction cost. A case study of a condominium building plan was analyzed in this research. The results found application of the mathematical model was applicable. The mathematical models were formulated, the minimum construction cost was 1723,000 (US\$24,100) and usable area in the condominium was $67.5 \mathrm{~m}^{2}$ and followed the assigned design constraints.
\end{abstract}

Keywords: Building plan design; Mathematical model; Unit cost;

eISSN 2398-4295 @ 2018. The Authors. Published for AMER ABRA cE-Bs by e-International Publishing House, Ltd., UK. This is an open-access article under the CC BY-NC-ND license (http://creativecommons.org/licenses/bync-nd/4.0/). Peer-review under responsibility of AMER (Association of Malaysian Environment-Behaviour Researchers), ABRA (Association of Behavioural Researchers on Asians) and CE-Bs (Centre for EnvironmentBehaviour Studies), Faculty of Architecture, Planning \& Surveying, Universiti Teknologi MARA, Malaysia.

DOI: http://dx.doi.org/10.21834/ajbes.v3i9.59 


\subsection{Introduction}

Design is the process in which intelligence and creativity are applied to a project in order to achieve an efficient and elegant solution, good design is not an optional extra, rather it is inherent in the way the brief is responded to from the very beginning. Design encompasses functional efficiency, structural integrity, sustainability, lifetime costing, and flexibility as well as responsiveness to the site and to its setting. Good design involves creativity, and it should lead to simplification and to savings in cost (Treasury Task Force, 2000). The "art" of architecture is what motivates most designers. This comes from the architect's view of self as an artist and relates to the architect's developed preferences for form, space, and meaning when responding to the other issues affecting design. However, most architects also want to understand and express the aesthetic preferences of clients, users, and society in the design. And, nearly all clients and users have legitimate goals and needs relative to the physical appearance of the buildings they occupy (Hershberger, 1999). Project financial feasibility analysis is an important pre-design service for most commercial, industrial, and housing facilities. A building whose cost exceeds budget can be devastating to both the client and the architect. If discovered during the design process, excessive building costs can be eliminated by reducing either the size of the building or the quality of materials and systems. On the other hand, this can involve the architect in a substantial amount of redesign if not discovered early in the design process.

Generally, architectural design uses a combination of knowledge both artistic and scientific to create a balance between the functions, aesthetics and economics of buildings. Building plan design is a part of architectural design which uses the knowledge. Consideration in economical aspect of designing dimensions and room sizes in a building plan, it means the most economical construction cost of the building. Estimation of the cost uses historical cost records of similar constructed buildings in estimating principle. A construction estimation method which generally used is the unit cost method which is the value of total direct cost for a production per the production output, the value called "unit cost". In the construction business, unit cost is construction cost per usable area of the building construction. Presently, the unit cost estimation is popularly used in predicting construction cost roughly before starting the construction. The unit cost can be classified in details of areas or rooms in a building such as living room, bathroom, and walkway. A difference of unit costs per each room/area depends on functions and construction costs of the rooms/areas.

Solving decision problems by using nonlinear programming which is a mathematical model technique which is an objective function and constraint functions are nonlinearity. Nonlinear programming technique designed to optimize the usage of limited resources. Successful applications of nonlinear programming exist in the areas of military, industry, agriculture, transportation, economics, health systems, and even behavioural and social sciences.

In this research, problem was to solve decision in building plan design. Dividing rooms and dimensions in a building plan of a building case study. The building plan where comprised of different rooms/functions with different construction costs. The difference of construction costs for each part of the building has effect on total construction cost of the 
building through different design patterns of the building plan. From this problem, mathematical model which is nonlinear programming can be used to solve the problem. Outputs of the model were to find out the minimum cost for construction and appropriate usable area in the building within design constraints.

\subsection{Objectives}

- To formulate mathematical models for analysis in dividing rooms and dimensions in a building plan of a building case study.

- To calculate and find out the dimensions and room sizes which have minimum construction cost.

\subsection{Scope of Study}

Scope of this research covered analysis and design of a condominium building plan where comprised of seven rooms by using the mathematical model technique. The seven rooms including: Living Room, Kitchen, Bath Room, Hall, Bed Room1, Bed Room2, and Bed Room3

Construction cost comprised of two parts. Firstly, construction cost of floors considering unit costs of construction per usable area $\left(\mathrm{B} / \mathrm{m}^{2}\right)$ by classifying functions of each room. Secondly, construction cost of walls considering unit costs of construction per wall area $\left(\mathrm{B} / \mathrm{m}^{2}\right)$ by classifying types of external and internal walls. Figure 1 was bubble diagram which presents relationships between areas in the building plan where designed by an architect and accorded with behaviors of uses and owner requirements.

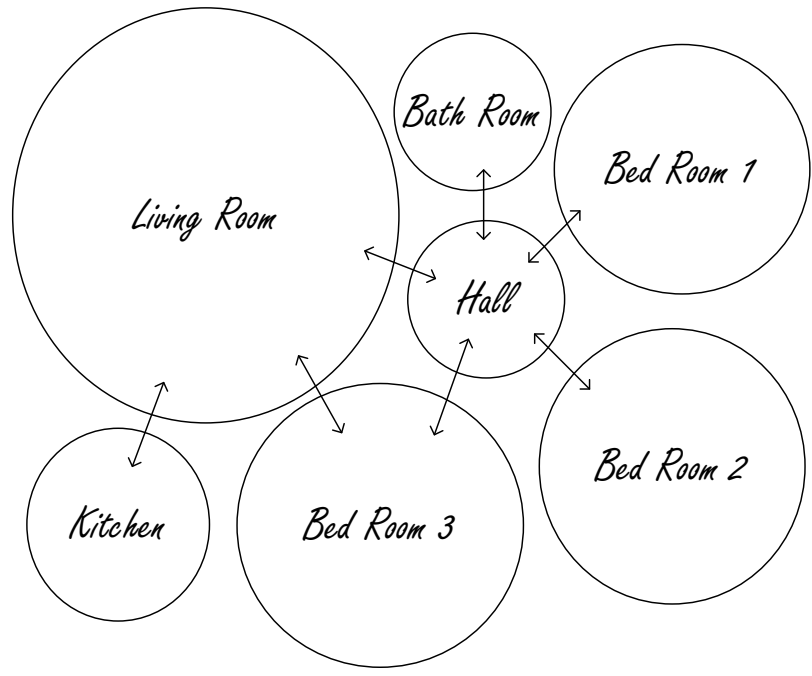

Figure 1: Bubble diagram of the building plan 
From the bubble diagram, the area relationships were developed to be preliminary plan of the building. Figure 2 presented the preliminary plan of the building before analysis.

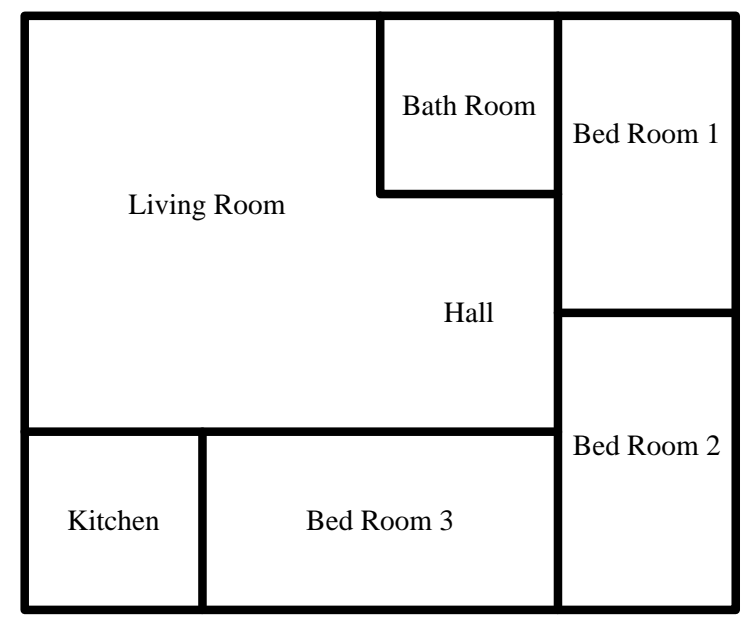

Figure 2: Preliminary plan of the condominium building (pre-analysis)

\subsection{Literature Review}

The "design process" is often described as an orderly arrangement of phases or steps. The design process involves numerous activities and tasks to bring about a solution. Some involve working with clients and others involved in the project. Some tasks require the preparation of graphic documents, such as floor plans and perspectives. Other tasks include researching information, such as applicable codes. And, of course, tasks also involve critical thinking, problem solving, and decision making. As for the design process itself, it has been recognized to involve five phases (design programming, schematic design, design development, contract documents, and contract administration), with many tasks in each phase as shown in Figure 3.

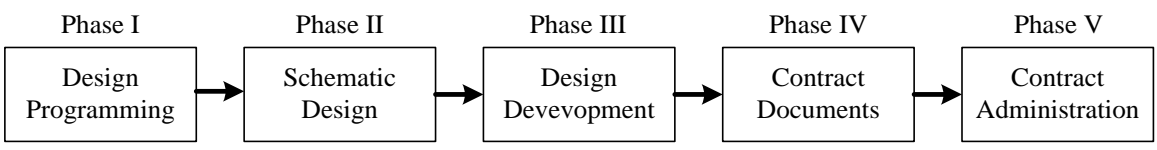

Figure 3: Five phases of the design process (Piotrowski, 2011)

In construction cost estimations, Ostward (2001) stated "unit method" uses historical and evidence and leads to a cost driver easily understood. The unit method is the most popular of all estimating methods. Examples of unit estimates are found in many business and economic activities: cost of house construction per square foot, cost of electrical 
transmission per mile, construction cost per hospital bed. Perhaps the most common unit cost estimate for buildings is the cost-per-square-foot. Area is perceived to have a powerful effect upon costs, and thus its popularity. The unit method is used extensively, such as average material prices, man hours, and labor cost. The unit estimate is defined as the mean, where the divisor is the principal cost driver. The use of this method should be restricted to the early stages of the design sequence and is probably the most frequently used method of approximate estimating. Its major advantage is that most published cost data is expressed in this form (Cartlidge, 2009).

"Linear programming" is a mathematical modelling technique designed to optimize the usage of limited resources (Taha, 1997). However, not all problems of allocating limited resources can be formulated to fit a linear programming model, even as a reasonable approximation. When one or more of the assumptions of linear programming is violated seriously, it may then be possible to apply another mathematical programming model instead (Hillier and Lieberman, 1990). In fact, many problems are nonlinearity in the real world; therefore, it often is necessary to deal directly with nonlinear programming problems. "Nonlinear programming" is a mathematical model which is an objective function and constraint functions are nonlinearity. Benefits and applications of nonlinear and linear programming are similar. Presently, linear and nonlinear programming software are generally used in personal computers for solving complex problems.

Balachandran, (1996) presented an application of multi-criteria optimization which nonlinear programming in design of a building plan. Objective functions in the study were minimized construction cost, maximized usable area and aspect ratio of building area. Constraint functions in the study were requirements of dimensions and room sizes. Parameters for measurements of differences of rooms were unit costs of construction costs per each room and construction costs per external and internal walls. Results shown optimization of room dimensions which were trade-offs between construction cost, usable area, and aspect ratio of building area.

\subsection{Methodology}

\subsection{Problem Formulation}

Problems in building plan design were studied and found that decision in designing dimensions and room sizes, considered variable was construction cost of the building. The construction cost comprised of two parts. Firstly, construction cost of floors by considering different unit costs of floor construction for different functions of each room. Secondly, construction costs of walls by considering different unit costs of wall construction for different types of external and internal walls. The difference of construction costs for each part of the building has effect on total construction cost of the building through different design functions of the building plan.

\subsection{Data Collection}

From the studied problems in the problem formulation, data were used in the analysis of the 
problems which researcher took to formulate the mathematical models which nonlinear programming included:

- From the preliminary plan of the building, setting up decision variables in to all dimensions in the building plan in vertical and horizontal axis of the plan.

- Collecting data regarding owner requirements in dimensions and room sizes of the building plan.

- Collecting data regarding building laws and regulations .

- Collecting data regarding unit costs of floor construction for each function of the seven rooms.

- Collecting data regarding unit costs of wall construction for external and internal walls. Implementing data collection, by discussing with the owner in requirements of dimensions and room sizes. And also, searching building local laws and regulations in building designs. Table 1 presented all design constraints in the building plan design.

Table 1: Constraints in the condominium building plan design

\begin{tabular}{|c|c|}
\hline Rooms & Design Constraints \\
\hline Living Room & $\begin{array}{l}\text { Owner requirements: living room should be at least } 5.00 \mathrm{~m} \text {. of width and at least } \\
5.00 \mathrm{~m} \text {. of length. }\end{array}$ \\
\hline Kitchen & $\begin{array}{l}\text { Owner requirements: kitchen should be at least } 2.00 \mathrm{~m} \text {. of width and length, at } \\
\text { least } 6.00 \mathrm{~m}^{2} \text { of area. }\end{array}$ \\
\hline Bath Room & $\begin{array}{l}\text { Owner requirements: bath room should be at least } 1.50 \mathrm{~m} \text {. of width and length, at } \\
\text { least } 3.00 \mathrm{~m}^{2} \text { of area. }\end{array}$ \\
\hline Hall & $\begin{array}{l}\text { Design constraints from size of door openings to the bed room } 1 \text { and } 2 \text { at least } \\
0.90 \mathrm{~m} \text {. per room according to size of the doors. }\end{array}$ \\
\hline Bed Room 1, 2, 3 & $\begin{array}{l}\text { Design constraints from building laws and regulations: bed room must be at least } \\
2.50 \mathrm{~m} \text {. of width and length; bed room must be at least } 8 \mathrm{~m}^{2} \text { of area. Owner } \\
\text { requirement: size of all bed rooms should be same sizes. }\end{array}$ \\
\hline
\end{tabular}

Then, searching construction cost from historical cost records of similar constructed buildings. Construction cost comprised of two parts. Firstly, construction cost of floors considering unit costs of construction per usable area $\left(\mathrm{B} / \mathrm{m}^{2}\right)$ by classifying functions of each room as shown in Table 2. Secondly, construction cost of walls considering unit costs of construction per wall area $\left(\mathrm{B} / \mathrm{m}^{2}\right)$ by classifying types of external and internal walls as shown in Table 3.

Table 2. Unit costs for construction of floors in the condominium building

\begin{tabular}{lllll}
\hline Rooms & Living Room and Hall & Kitchen & Bath Room & $\begin{array}{l}\text { Bed Room } \\
1,2,3\end{array}$ \\
\hline Construction Cost & $6,000 \mathbb{B} / \mathrm{m}^{2}$ & $12,000 \mathrm{~B} / \mathrm{m}^{2}$ & $10,000 \mathrm{~B} / \mathrm{m}^{2}$ & $8,000 \mathrm{~B} / \mathrm{m}^{2}$ \\
\hline
\end{tabular}


Ngowtanasuwan, G. / Asian Journal of Behavioural Studies (AjBeS), 3(9) Jan / Feb 2018 (p. 39-49)

Table 3. Unit costs for construction of walls in the condominium building

\begin{tabular}{lll}
\hline Walls & External Wall & Internal Wall \\
\hline Construction Cost & $1,500 \mathrm{~B} / \mathrm{m}^{2}$ & $1,000 \mathrm{~B} / \mathrm{m}^{2}$ \\
\hline
\end{tabular}

\subsection{Model Formulation}

Formulating mathematical models in this research were nonlinear programming which comprised of three main parts included:

\subsubsection{Decision Variables}

From the preliminary plan of the building, setting up decision variables in to all dimensions in the building plan in vertical and horizontal axis of the plan. Decision variables were dimensions of the rooms in the building plan. Horizontal axis: $X 1, X 2, X 3$, and $X 4$ vertical axis: $X 5, X 6, X 7$, and $X 8$ as shown in Figure 4 .
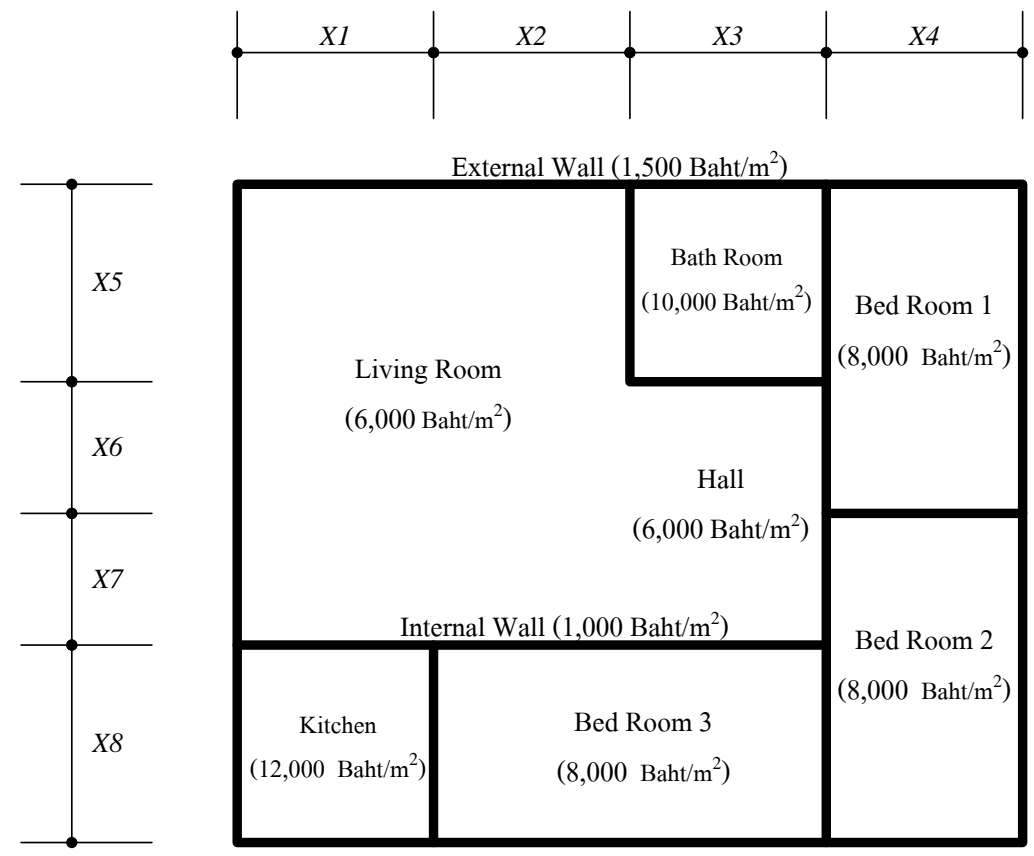

External Wall $\left(1,500 \mathrm{Baht} / \mathrm{m}^{2}\right)$

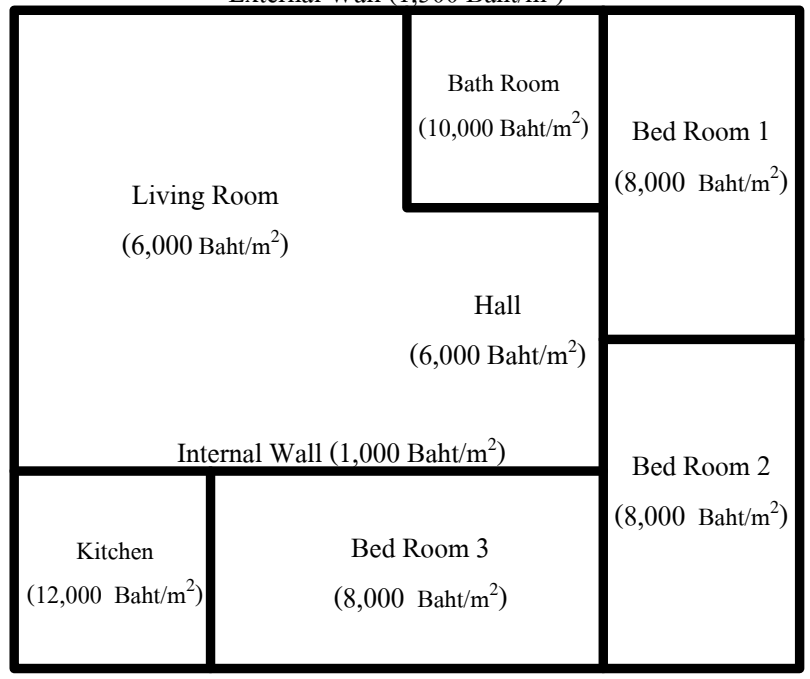

Figure 4: Preliminary plan of the condominium building with dimensions of decision variables and unit costs 


\subsubsection{Objective Function}

Objective function in this research was objective which minimum construction cost $(\square)$. From collected data, formulating objective function which is nonlinear programming equation was defined as follows:

Minimum construction cost $=\left(\right.$ living room area ${ }^{*}$ unit cost of living room $)+\left(\right.$ hall area ${ }^{*}$ unit cost of hall) + (kitchen area*unit cost of kitchen + (bath room area*unit cost of bath room) + (bed room $1^{*}$ unit cost bed room 1$)+\left(\right.$ bed room $2^{*}$ unit cost bed room 2$)+\left(\right.$ bed room $3^{*}$ unit cost bed room3) + (total length of external walls*height of external wall* unit cost of external wall) + (total length of internal walls*height of external wall *unit cost of internal wall) MIN.COST $=(X 1+X 2)^{*}(X 5+X 6+X 7)^{*} 6,000+(X 6+X 7)^{*} X 3^{*} 6,000+X 1^{*} X 8^{*} 12,000+X 3^{*} X 5^{*} 10,000$ $+(X 5+X 6)^{*} X 4^{*} 8,000+(X 7+X 8)^{*} X 4^{*} 8,000+(X 2+X 3)^{*} X 8{ }^{*} 8,000+(X 1+X 2+X 3+X 4+X 5+X 6+X 7+$ $X 8)^{*} 2^{*} 3^{*} 1,500+\left(X 1+X 2+2^{*} X 3+X 4+2^{*} X 5+X 6+X 7+2^{*} X 8\right)^{*} 3^{*} 1,000$

\subsubsection{Constraint Functions}

Constraint functions included owner requirements in room sizes, building laws and regulations and other constraints. The constraints were:

3.3.3.1 Living Room: owner required living room should be at least $5.00 \mathrm{~m}$. of width and at least $5.00 \mathrm{~m}$. of length. Constraint functions were formulated as follows:

$X 5+X 6+X 7>=5$

$X 1+X 2>=5$

3.3.3.2 Kitchen: owner required kitchen should be at least $2.00 \mathrm{~m}$. of width and length, at least $6.00 \mathrm{~m}^{2}$ of area. Constraint functions were formulated as follows:

$X 1>=2$

$X 8>=2$

$X 1 * X 8>=6$

3.3.3.3 Bath Room: owner required bath room should be at least $1.50 \mathrm{~m}$. of width and length, at least $3.00 \mathrm{~m}^{2}$ of area. Constraint functions were formulated as follows:

$X 3>=1.5$

$X 5>=1.5$

$X 3^{*} \times 5>=3$

3.3.3.4 Hall: design constraints from size of door openings to the bed room 1 and 2 at least $0.90 \mathrm{~m}$. per room according to size of the doors. Constraint functions were formulated as follows:

$X 6>=0.9$

$X 7>=0.9$

3.3.3.5 Bed Room1: design constraints from building laws and regulations: bed room1 must be at least $2.50 \mathrm{~m}$. of width and length; bed room1 must be at least $8 \mathrm{~m}^{2}$ of area. Constraint functions were formulated as follows: 
$X 4>=2.5$

$X 5+X 6>=2.5$

$X 4^{*}(X 5+X 6)>=8$

3.3.3.6 Bed Room2 design constraints from building laws and regulations: bed room 2 must be at least $2.50 \mathrm{~m}$. of width and length; bed room2 must be at least $8 \mathrm{~m}^{2}$ of area. Constraint functions were formulated as follows:

$X 7+X 8>=2.5$

$X 4^{*}(X 7+X 8)>=8$

3.3.3.7 Bed Room3 design constraints from building laws and regulations: bed room3 must be at least $2.50 \mathrm{~m}$. of width and length; bed room 3 must be at least $8 \mathrm{~m}^{2}$ of area. Constraint functions were formulated as follows:

$X 8>=2.5$

$X 2+X 3>=2.5$

$X 8^{*}(X 2+X 3)>=8$

3.3.3.8 Bed Room1, 2, and 3: owner required size of all bed rooms should be same sizes. Constraint functions were formulated as follows:

$X 4-X 8=0$

$X 2+X 3-X 5-X 6=0$

$X 5+X 6-X 7-X 8=0$

\subsection{Findings and Analysis}

Data analysis in this research, researcher inputted the data in to a personal computer by using a nonlinear programming software for the data analysis; the data included equation (1) to (22) from the model formulation. After running the models, the following output had been obtained. The results were shown in Table 4.

Table 4. Results from the data analysis by nonlinear programming software

\begin{tabular}{llllllllll}
\hline$X 1$ & $X 2$ & $X 3$ & $X 4$ & $X 5$ & $X 6$ & $X 7$ & $X 8$ & Construction Cost $(\mathbb{B})$ & Usable Area $\left(\mathrm{m}^{2}\right)$ \\
\hline 2.75 & 2.25 & 1.50 & 2.50 & 2.00 & 1.75 & 1.25 & 2.50 & 723,000 & 67.50 \\
\hline
\end{tabular}

From the results, the preliminary building plan was drawn output numbers of the dimensions $X 1$ to $X 8$ in to the plan. The condominium building plan was analyzed and designed as shown in Figure 5. 

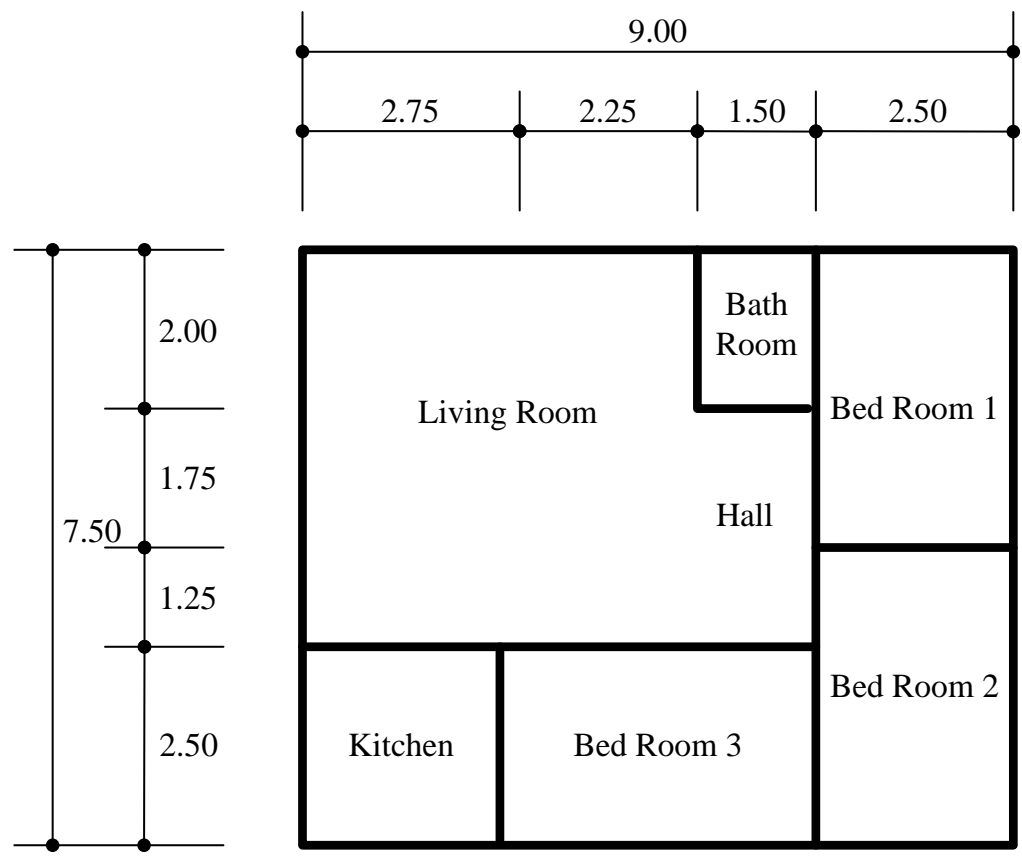

Figure 5.The condominium building plan was analyzed and designed

\subsection{Conclusion}

This article presents a method for solving decision in building plan design. By using a mathematical model which nonlinear programming for dividing rooms and dimensions in a building plan. Outputs of the model were to find out the minimum cost for construction and appropriate usable area in the building within design constraints such as owner requirements in room sizes, building laws and regulations, construction costs of floor per each room and construction costs of external and internal walls by using the unit cost method in construction estimation. From a case study of a condominium building plan was analyzed and calculated in this research. The results found that application of the mathematical model in the decision was applicable. The mathematical models of the case study were formulated as shown in equation (1) to (22), results shown the minimum construction cost was $\mathbb{B} 723,000$ (US $\$ 24,100)$ and usable area in the condominium was $67.5 \mathrm{~m}^{2}$. The dimensions $X 1=2.75$ m., $X 2=2.25 \mathrm{~m}$., $X 3=1.50 \mathrm{~m}$., $X 4=2.50 \mathrm{~m}$., $X 5=2.00 \mathrm{~m}$., $X 6=1.75 \mathrm{~m} ., X 7=1.25 \mathrm{~m}$. and $X 8=2.50 \mathrm{~m}$. dimensions and rooms of the building were designed and followed the assigned design constraints. The results shown the application of the mathematical model which is nonlinear programming technique in this research was applicable effectively by the obtained results were the most economical construction cost of the building. By using this model, an architect will be able to choose the best solution based on the construction cost aspect. 
Applications of the mathematical model can be applied to other more complicated building plans such as a part of circle building plans, triangle building plans, or other geometry plans where can be formulated and calculated the building plan areas. Moreover, the constraint functions can be added more other requirements such as required room sizes for furniture sizes, or other conditions.

The applications of the mathematical model can also be applied to other objective functions for example, usable area in the building within construction cost budget. The objective function can be applied to multi-criteria optimization (more than one objective function) such as minimized construction cost, maximized usable area and aspect ratio of building area.

\section{Acknowledgement}

This research was supported funding by the research project grant provided by faculty of Architecture Urban design and Creative Arts, Mahasarakham University, Thailand.

\section{References}

Balachandran M. (1996). "Knowledge-Based Optimum Design". Computation Mechanics Publications 1993. Southamton UK and Boston USA. P.35-49

Cartlidge, Duncan (2009). "Quantity Surveyor's Pocket Book" 1st edition. Elsevier Ltd. Oxford. P.39-40

Hillier S. Frederick and Lieberman J. Gerald. (1990). "Introduction to Operations Research". $5^{\text {th }}$ ed. McGraw-Hill Book Co. Singapore. P.499

Hershberger, Robert G. (1999). "Architectural Programming and Predesign Manager". McGraw-Hill Companies, Inc. New York.

Ostwald F. Phillip. (2001). "Construction Cost Analysis and Estimating”. Prentice-Hall, Inc. New Jersey. P.195-196

Piotrowski, Christine M. (2011) "Problem Solving and Critical Thinking for Designers". John Wiley \& Sons, Inc., Hoboken, New Jersey. P.14-16

Taha Hamdy A. (1997). "Operations Research an Introduction". Prentice-Hall International, Inc. New Jersey. P.11 Treasury Task Force (2000). "How to Achieve Design Quality in PFI Projects", Technical Note 7. HM Treasury, London. 